\title{
Ideología y poder en el anime japonés La princesa Mononoke
}

\author{
Tania Lucía Cobos Cobos \\ Tecnológico de Monterrey, campus Monterrey
}

Recibido: 31/10/2011

Aprobado: 07/12/2011

\begin{abstract}
RESUMEN: El presente documento realiza una revisión teórica del discurso presente en la película de animación japonesa titulada La princesa Mononoke (1997) del director Hayao Miyazaki. Se analiza el componente ideológico visto desde los postulados de Teun van Dijk, y las relaciones de poder desde la óptica de Michel Foucault.
\end{abstract}

Palabras clave: Princesa Mononoke / análisis del discurso / ideología / poder

\section{Ideology and power in the Japanese anime The princess Mononoke}

\begin{abstract}
Summary: This paper makes a theoretical revision of the underlined themes presented in the Japanese animation movie titled The princess Mononoke (1997) from director Hayao Miyazaki. It analyzes the ideological component from the perspective of Teun van Dijk's postulates and the relationships of power from the views of Michel Foucault.
\end{abstract}

Keywords: Princess Mononoke / discourse analysis / ideology / power relations 
$\mathrm{E}$ n la diversidad de noticias generadas por los medios de comunicación de Occidente, los postulados sobre discurso e ideología del lingüista holandés Teun van Dijk han sido implementados en el análisis de temas socialmente sensibles como el racismo moderno, el terrorismo, la legitimación de la guerra y los inmigrantes. Estos temas, a su vez, suelen ser constantes en la agenda de los medios, y México no es la excepción.

Sin embargo, hay una pluralidad de discursos ideológicos que los medios de comunicación occidentales no marcan en sus agendas, pero que están ahí latentes, llegando a una audiencia a través de formas alternativas. Lo alternativo no es solo la forma, sino también el contenido. La llegada de internet como una nueva tecnología de comunicación e información, y con esta el video por demanda y el video streaming, ha cambiado la forma como se consume cine y televisión, no solo porque se vea desde el computador sino también porque facilita la consecución de referencias sobre qué ver o no. $\mathrm{Y}$ en el contenido, al favorecer la diversificación de la oferta de programas y películas provenientes, entre otras latitudes, de Asia.

Este documento se propone hacer un análisis del discurso ideológico de la película de animación japonesa Mononoke Hime (1997) (Mononoke: espíritu vengador; Hime: princesa), conocida en Latinoamérica como $\mathrm{La}$ princesa Mononoke, del premiado ci- neasta nipón Hayao Miyazaki y su productora Estudio Ghibli. Asimismo, profundizar en uno de sus personajes protagónicos, Lady Eboshi, y la relación ideología-poder que se evidencia entre ella y los habitantes de la Ciudad del Hierro.

Puede resultar paradójico para algunos el análisis de una película animada concebida bajo un marco cultural oriental, en este caso japonés, utilizando las teorías postuladas por intelectuales europeos y en un contexto latinoamericano; sin embargo, se considera que dada la dinámica de globalización que se vive a la fecha, la lectura de aceptación, rechazo o negociación de este discurso por quien lo reciba se hará bajo el contexto al que ha estado expuesto la mayor parte del tiempo.

Parafraseando a Van Dijk (2005), la ideología es un sistema de creencias fundamentales o axiomáticas de naturaleza bastante general y abstracta que son socialmente compartidas por los miembros de una colectividad, y que a su vez, estas controlan y organizan otras creencias socialmente compartidas. Dicho de otro modo, consiste en representaciones sociales que definen la identidad social de un grupo, es decir, sus creencias conjuntas acerca de sus condiciones fundamentales y sus modos de existencia y reproducción.

El autor sostiene que la ideología tiene funciones cognoscitivas, una de ellas es proporcionar coherencia a las creencias del grupo para así facilitar 
su apropiación y uso en situaciones de la vida diaria; asimismo, especifica cuáles son los valores culturales (libertad, igualdad, justicia...) importantes para el grupo. También permite a los miembros coordinar y organizar sus acciones conjuntas y sus interacciones con miras a las metas e intereses del grupo, y funcionan como la parte interfaz entre las estructuras sociales de grupos por un lado y sus discursos y otras prácticas sociales por el otro.

En vista de sus funciones sociales, el autor se aventura a suponer o esbozar un esquema ideológico general que consiste en un conjunto de categorías básicas que definen la autoidentidad de los grupos (criterio de identidad, actividades típicas, objetivos, normas y valores, grupos relacionados y recursos o falta de recursos básicos), sin embargo, como él lo reconoce, es un aspecto que aún cuenta con lagunas y debe ser profundizado.

El proceso de adquisición de una ideología es gradual, dice Van Dijk, se logra después de muchas experiencias y discursos, y puede, a veces, cambiar en algún período en el transcurso de la vida. Asimismo, en un proceso paralelamente inverso, las ideologías también pueden desaparecer. Según el autor, hay diferentes tipos de ideologías que son definidas por los tipos de grupos que "tienen" una ideología (movimientos sociales, partidos políticos, gremios profesionales, iglesias...). Por ejemplo, una ideología racista puede controlar actitudes sobre la migración.
Van Dijk (2000) afirma que la ideología tiene una intención persuasiva ya que los hablantes, más allá de hacer un despliegue explícito u oculto de sus creencias, buscan cambiar la mentalidad de sus receptores de una forma que sean congruentes con sus creencias, intenciones y objetivos. Así, la ideología, en palabras del citado autor, puede funcionar para legitimar la dominación pero también para articular la resistencia en las relaciones de poder, o también como una base de "pautas" de conducta profesional.

Tal como se exponía al inicio del documento, se plantea como primer aspecto un análisis ideológico de un discurso. En este sentido, Van Dijk (1996) opina que este tipo de análisis se considera como un tipo específico de análisis de discurso sociopolítico, donde el lenguaje juega el papel articulador clave entre el discurso y la ideología.

El discurso está complejamente relacionado y condicionado por las ideologías que convergen en cada persona, afirma, y que no siempre se van a evidenciar de forma clara y transparente, también pueden estar ocultas o disimuladas. Por ejemplo, el discurso de una periodista estadounidense de raza negra estará influenciado por la ideología de la afroamericanidad, la ideología de ser estadounidense, la ideología del ser periodista, la ideología del medio donde trabaja e incluso una ideología feminista, además de que unas primarán más que otras. 
Lo anterior dificulta el análisis ya que no es posible inferir con total certeza cuáles son las creencias ideológicas de quien lo pronuncia, sumando además la influencia del contexto donde se pronuncia y las varianzas que pueden darse en cada reproducción. Por tal razón, Van Dijk (2000) afirma que el concepto de ideología no es determinista; sin embargo, queda claro que las ideologías son adquiridas, expresadas, promulgadas y reproducidas por el discurso.

Por otro lado, teniendo en cuenta el segundo aspecto planteado para este análisis, se manifiesta la intrínseca o íntima relación que existe entre la ideología y el poder. Ávila-Fuenmayor (2007) sustenta que de manera general poder significa "ser capaz, tener fuerza para algo, o lo que es lo mismo, ser potente para lograr el dominio o posesión de un objeto físico concreto, o para el desarrollo de tipo moral, político o científico". Poder deriva del latín possum, indica el citado autor, que se interpreta como ser potente o capaz, al igual que alude a tener influencia, imponerse y ser eficaz. El poder no es una propiedad, es una estrategia, es decir, no se posee, se ejerce.

Foucault (1984) indica que:

[...] lo que define una relación de poder es un modo de acción que no actúa directa e inmediatamente sobre los otros, sino que actúa sobre su propia acción. Una acción sobre la acción, sobre acciones eventuales o concretas, futuras o presentes.
Y agrega que para que una relación de poder se articule se necesitan:

[...] dos elementos que son indispensables para que sea justamente una relación de poder: que el "otro" (aquel sobre el cual se ejerce) sea reconocido y permanezca hasta el final como sujeto de acción; y que se abra ante la relación de poder todo un campo de respuestas, reacciones, efectos, invenciones posibles.

En el caso de la violencia, se sucede una relación de violencia donde esta fuerza doblega, quiebra, destruye cosas o cuerpos, por lo que solo pueden generarse dos respuestas en el violentado: pasividad o resistencia, y si surge esta última, solo queda la opción de reducirla.

El uso de las relaciones de poder, como afirma el citado autor, no se basa solo en obtener el consentimiento del otro o en la violencia, usualmente para ejercerlo son necesarios e imprescindibles ambos. Este ejercicio del poder se caracteriza como el "gobierno" de unos hombres sobre otros. Los gobernados son "sujetos libres" y esa libertad se caracteriza por que estos, sean individuos o colectividades, tienen ante sí un campo de posibilidades en el cual se pueden dar diversas conductas, reacciones y modos de comportamiento. El poder y la libertad no están enfrentados ni mantienen una relación de exclusión, la libertad es una condición de existencia del poder. La esclavitud, o ausencia de libertad, no es una relación de poder, es una relación físi- 
ca de coerción. Por otra parte, el ejercicio de poder requiere una estrategia de poder, entendida como el conjunto de medios que se utilizan para funcionar o hacer mantener el dispositivo de poder, afirma Foucault (1984).

La ideología es un concepto íntimamente relacionado con el poder afirma Mager (2010), ya que esta lo utiliza como instrumento:

Aunque la ideología se constituye en un conjunto de ideas, en el fondo actúan intereses de un poder dominante, lo que nos acerca al poder indirecto que busca convencer a los otros de manera suave para que se adapten.

El poder suave no es otro que el poder ideológico, concepto de Joseph Nye (2004) que significa "hacer que los otros quieran lo que tú quieres".

En este documento, como ya se expresaba, se propone un análisis al discurso ideológico o análisis de discurso sociopolítico de la película de animación japonesa La princesa Mononoke de Hayao Miyazaki y profundizar en uno de sus personajes protagónicos, Lady Eboshi, y la relación ideología-poder que se evidencia entre ella y los habitantes de la Ciudad del Hierro.

Estrenada en su natal Japón, en julio de 1997, después de permanecer dieciséis años en producción, Mononoke Hime logró posicionarse como la película más taquillera de ese año, desbancando a la estadounidense $\mathrm{Ti}$ tanic de James Cameron y recaudando 18.650 millones de yenes (más de 2.669 millones de pesos mexicanos). Cuenta en su haber con una treintena de premios ganados en festivales de cine, la gran mayoría japoneses.

Su éxito llamó la atención y le abrió las puertas al Estudio Ghibli para exportar oficialmente su producción cinematográfica a Occidente a través de Walt Disney Company, que adquirió los derechos exclusivos; sin embargo, las proyecciones de las películas de esta productora en Estados Unidos y América Latina carecen de la misma estrategia publicitaria con que se anuncian las películas de la factoría Disney. Usualmente sus estrenos no se divulgan y duran un corto tiempo en cartelera o simplemente no se hacen, pasando directo a la venta en tiendas.

De acuerdo con la Internet Movie Database IMDb, la película llegó a Estados Unidos en 1999 a manos de Miramax Films (subsidiaria de Disney), donde fue doblada al inglés usando star-talents ${ }^{1}$ y estrenada en pocas salas y por un corto tiempo. Por otro lado, según Anime News Network, esta misma empresa, a través de Musitrón S.A de C.V, se encargó del doblaje de la película al español latino, ${ }^{2}$ que se lle-

1 Nombre con el que se designa el cast de actores y actrices famosos de cine y televisión que son llamados para realizar un doblaje.

2 La versión latina se basó en la versión en inglés, no fue traducida directamente del japonés. 
vó a cabo en la ciudad de Monterrey (México), para su distribución a través de Disney/Buenavista en VHS. Posteriormente, en el 2010, la película fue re-doblada ${ }^{3}$ en Ciudad de México por Zima Entertaiment para su distribución en DVD. No se encontró evidencia de que la película fuera estrenada comercialmente en cines mexicanos, como sí se ha hecho con otras películas de este cineasta, y a la fecha, se puede adquirir en formato DVD en México, en tiendas como Samborns, Blockbuster y similares.

Internet jugó un papel fundamental en la obtención de mayor información y distribución de este contenido en Latinoamérica. Las primeras referencias sobre esta obra se hayan al principio de la década del dos mil. Seguidores mexicanos de este género ${ }^{4}$ afirmaron que habían comprado el VHS latino o el DVD estadounidense en tiendas o por internet y otros que habían utilizado este medio para descargarla (video por demanda) y en años más recientes, para verla en línea (video streaming).

La historia está ambientada en Japón, en el período Muromachi ${ }^{5}$ tardío, con la inclusión de elementos fantásticos. Se centra en la lucha entre los guardianes sobrenaturales de un bosque (Shishigami, el espíritu del bosque, y los dioses menores) y una población de seres humanos invasora (la Ciudad del Hierro gobernada por Lady Eboshi), que destruye la foresta para obtener hierro y de esa forma asegurar la subsistencia de la ciudad.

Ashitaka, el príncipe heredero del Clan Emishi, sufre una maldición al matar en defensa de su pueblo al jabalí Nago, uno de los dioses menores que se ha convertido en un tatarigami. ${ }^{6}$ En las entrañas de este descubren una bola de hierro que hace pensar que ha sido la causante del sufrimiento y la ira incontrolable de la bestia. Exiliado, Ashitaka emprende un viaje hacia el oeste, acompañado de su alce Yakul, para encontrar una cura a la maldición que lo ha condenado a muerte, pero que a su vez le proporciona una fuerza sobrenatural. Así, se ve envuelto en medio de la disputa, donde aparece San, la princesa de los mononoke, una joven humana de aspecto fantasmal que convive con una manada de lobos que intenta acabar con Lady Eboshi. Ashitaka entra a mediar e intenta convencer a ambas partes para lograr una salida pacífica al conflicto y encuentren, seres humanos y naturaleza, una manera de convivir, sin embargo, sus esfuerzos no son suficientes y la guerra es inminente.

3 Se tuvo la oportunidad de ver la película en sus dos doblajes latinos, siendo el primero más fiel a los diálogos originales en japonés que el segundo.

4 Quienes fueron contactados por la autora vía Facebook y Twitter.

5 Época de Japón que comprende entre el año 1336 a 1573 bajo el shogunato de los Ashikaga.

6 En la mitología japonesa, es un demonio que destruye todo lo viviente tan solo con tocarlo. 
En la película están presentes otros personajes de carácter secundario. Shishigami o el Gran Espíritu del Bosque (también llamado el Dios Ciervo), el dios antiguo de la creación y la destrucción que vive en el bosque; Hi-san, la anciana sacerdotisa del Clan Emishi; Moro, una loba, diosa menor que protege junto a sus cachorros y San el bosque; Koroku, uno de los hombres que cae al barranco luego de ser emboscado por los lobos; Toki, la esposa de Koroku; Gonza, el lugarteniente principal de Lady Eboshi; Jiko, se presenta como un monje, pero al parecer es un espía del emperador Mikado, le pide a Lady Eboshi aliarse con él para cortarle la cabeza al Shishigami; Kodama, pequeños espíritus de los árboles que usualmente habitan bosques espesos; Okkoto, otro dios jabalí que viene de las islas del sur para proteger el bosque; y Asano, un enemigo de Lady Eboshi que desea apoderarse de su hierro.

En la película se evidencian tres sistemas de creencias o ideologías, sin embargo, las que más se desarrollan (de las que más se conocen elementos) son las de los protagonistas de esta, Ashitaka del Clan Emishi y Lady Eboshi de la Ciudad del Hierro. La tercera está representada por los dioses menores del bosque. Las ideologías protagonistas, aunque son marcadamente diferentes, no llegan a enemistarse o a desplegar abiertamente un conflicto.

La primera ideología en manifestarse es la del Clan Emishi, cuyo princi- pal exponente es Ashitaka, el príncipe heredero. Se caracteriza por acciones como obediencia a la palabra de los ancianos, el intento de establecer un diálogo con el enemigo antes de optar por la fuerza bruta, el ataque como recurso de defensa, el respeto hacia las demás criaturas de la naturaleza (no se está por encima ni por debajo de estas, sino en estado de igualdad), el compañerismo, el agradecimiento (tanto por las cosas positivas como por las negativas), respeto hacia los dioses (mas no temor), y convivencia autosostenible con el medio ambiente que les rodea. Asimismo, expone que los sentimientos de ira y odio no traen más que destrucción, por eso su actitud permanente al lidiar con los dioses menores (encabezados por San y Moro) y con Lady Eboshi, es lograr un acuerdo que les permita a ambos convivir pacíficamente en el bosque del Shishigami.

Durante toda la película, los discursos o diálogos de este personaje evidencian en todo momento su ideología, que tampoco se ve alterada o trastocada al entrar en contacto con las otras. Se pueden citar varias situaciones que ejemplifican lo anterior. Cuando aparece el dios Nago en su poblado convertido en tatarigami, Ashitaka le dice continuamente mientras huye de él: “¡Tranquilízate, oh gran señor! Dios o demonio, cualquier cosa que seas, ¡por favor déjanos en paz! [...] ¡No sigas por favor! ¡Deja nuestra aldea en paz! [...] ¡Detente! ¡Por favor detente!”. 
En vista de que sus palabras no son escuchadas, Ashitaka primero le dispara una flecha de advertencia que lo hiere en un ojo, y finalmente otra en el centro de la cabeza que termina matándolo. En otra escena, cuando Ashitaka marcha exiliado con Yakul, pasa por una población que está siendo atacada por samuráis, ${ }^{7}$ ellos lo ven y arremeten contra él, Ashitaka les grita “ ¡Déjenme pasar! ¡Se los advierto!" (Ashitaka descubre que la maldición de su brazo se activa en situaciones de ira y odio), estos lo ignoran y continúan el ataque, por lo que Ashitaka dispara una flecha que le corta los brazos a uno y a otro la cabeza; el tercero, al ver esto, emprende la huida y Ashitaka no lo persigue.

Ashitaka es el único personaje que no toma partido por alguno de los actores del conflicto. Cuando conoce a Lady Eboshi en la Ciudad del Hierro y esta le pregunta cuáles son sus intenciones, Ashitaka le responde "observar con los ojos despejados". En otro momento, cuando se encuentra en una caverna recuperándose de sus heridas y conversa con Moro, ella le pregunta si unirá fuerzas con San (de quien él se ha enamorado) a lo que responde "no, eso solo causaría más odio".

Este personaje entiende que la polarización de ambos bandos no es la salida al conflicto y a lo largo de la pelí- cula se le muestra intentando dialogar con uno y otro resultando un esfuerzo infructuoso. En una escena, cuando Ashitaka está en una cueva recuperándose de una herida, conversando con Moro, le cuestiona “ ¿No pueden vivir humanos y el bosque juntos en paz?, ¿no se puede detener esto?". Asimismo, Ashitaka muestra la maldición que carga su brazo como una forma de escarmiento público para ambos bandos que se han empeñado en destruirse mutuamente. Lady Eboshi y San se están enfrentando cuerpo a cuerpo, Ashitaka se mete en medio y las detiene, pero al ver que ellas no cejan, les da un puño en el estómago a cada una y ambas caen desmayadas. Ashitaka les dice a los presentes: "Miren, así es como luce el odio, esto es lo que provoca cuando se apodera de ustedes. Está comiéndome vivo y muy pronto terminará matándome".

Ashitaka manifiesta respeto por todos aquellos que le rodean. Cuando llega al bosque del Dios Ciervo, junto con Koroku y el otro hombre herido, se les aparecen los Kodama, Ashitaka se acerca a uno de ellos y cortésmente le dice "¿serías tan amable de permitirnos pasar en medio de tu bosque pequeñín?", esta misma actitud se evidencia posteriormente cuando lo han atravesado, guiado por los Kodama,

7 Se utiliza con frecuencia para referirse a una gran variedad de antiguos guerreros japoneses. Fue una élite militar que gobernó Japón durante cientos de años, tuvo su apogeo en el período Sengoku (1467-1615). 
y llegan a un árbol gigante, Ashitaka

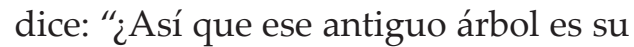
madre?, es muy hermosa". Al principio de la película, este comportamiento también es replicado por Hi-san, la anciana sacerdotisa del Clan Emishi. Al caer abatido Nago, ella se le acerca, le brinda sus respetos y le promete construir una tumba en el lugar donde ha caído así como rituales para honrar su memoria, "Oh dios desconocido de la furia y el odio, me inclino ante ti. Levantaremos una tumba y efectuaremos un funeral donde has caído. Ve en paz y no nos guardes rencor", dice.

Finalmente, otros aspectos que evidencian la ideología que guía las acciones de este personaje se reflejan por ejemplo cuando Ashitaka manifiesta agradecimiento por los cuidados y atenciones y hasta las no gratas experiencias que vive tanto en su Clan como en los bandos de los dioses menores y Lady Eboshi. Asimismo, la relación de compañerismo y apoyo que se evidencia durante toda la película entre Ashitaka y Yakul, que más que su montura es su compañero de travesía.

La segunda ideología en manifestarse, y quizás la que más protagonismo tiene en la película, es la encarnada por el personaje de Lady Eboshi, la gobernadora de la Ciudad del Hierro. La Ciudad del Hierro se encuentra enclavada en las montañas totalmente deforestadas por la actividad minera. Los árboles talados se han utilizado para construir los muros y las empalizadas que la defienden, así como la madera que necesitan para construir las viviendas y en la forja del hierro. Las chimeneas de la fundición humean constantemente hacia el cielo y el agua del río es usada para lavar la tierra durante la extracción del metal. Por dentro es una ciudad bulliciosa, llena de hombres y mujeres que trabajan principalmente en la extracción y fundido del metal.

La personalidad de Lady Eboshi es más compleja que cualquiera de los otros personajes que aparecen, y su ideología se caracteriza principalmente por la instrumentalización, todos los recursos que se encuentran a su alrededor, incluso los habitantes de la Ciudad del Hierro, son instrumentos para lograr la supervivencia de la comunidad ( ¿o la de ella y su negocio del hierro?), sin reparar en la destrucción que ocurra ni los efectos que se generen sobre otros seres (aunque esto no implica que se rehúse a asumir las consecuencias de sus actos). Ejemplo de lo anterior sucede cuando Moro con San y los lobos cachorros atacan la caravana de Lady Eboshi, que lleva decenas de sacos de arroz a la ciudad, varios hombres caen al barranco (entre ellos Koroku) y Gonza pregunta “iqué hay de los hombres que cayeron al barranco?", a lo que ella responde "Reorganicen y continúen".

Su posición con respecto a los dioses es diferente, si bien los respeta por lo fuertes que son, también es consciente de la mortalidad de estos. La percepción de que no son más que 
elementos molestos que le dificultan el camino se evidencia en varios momentos. Por ejemplo, cuando están en el barranco y Lady Eboshi le dispara a Moro, sus hombres exclaman "iLa matamos!", a lo que ella calmadamente responde "Se te olvida que es una diosa, necesitamos mucho más para deshacernos de ella". Esta misma actitud se replica cuando se encuentra en la Ciudad del Hierro y está reunida con las mujeres avisándoles que partirá con Jiko, ella les dice "temo más a los humanos que a los dioses del bosque" y posteriormente, cuando están en el estanque dentro del bosque, ella arremete con su fusil contra el Shishigami exclamando “iLes enseñaré cómo se mata un dios, un dios de la vida y la muerte, el secreto es no temerle!".

Los mismos hombres de la Ciudad del Hierro reconocen esta actitud de Lady Eboshi al decirle a Ashitaka que ella no le teme a las antiguas leyes o maldiciones, ni a dioses, y le cuentan cómo desafió y enfrentó a uno de ellos, Nago. Además, las actitudes de estos para con ellos también son similares, por ejemplo, cuando Ashitaka está con Koroku y el otro hombre herido en el bosque, la reacción de Koroku es de temor/disgusto cuando se les aparecen los Kodama, gesto que repite cuando Ashitaka brinda sus respetos al árbol madre de los Kodama. Curiosamente, al final de la película, cuando están todos los pobladores de la Ciudad del Hierro en el lago, Koroku comenta:
"No sabía que el Shishigami hacía florecer a las plantas".

De igual manera, Lady Eboshi desdeña la labor que cumplen los dioses menores, por ejemplo, cuando está con Ashitaka probando una nueva arma, ella dispara hacia la montaña para ahuyentar a los simios y dice: "Oh, siempre regresan. Cada noche salen a reforestar el bosque. Tratan de convertir esa montaña en un bosque de nuevo", la evidencia más clara que motiva sus acciones se lo confiesa a Ashitaka en esa misma escena al decirle: "Sin el Shishigami, los animales volverán a ser las bestias de siempre. Cuando talemos todo el bosque y exterminemos a los lobos, este lugar desolado será la tierra más rica del mun$\mathrm{do}^{\prime \prime}$, esa riqueza se refiere al hierro, tal como más adelante le dice a Jiko refiriéndose a los ataques de Asano: "Quiere mi hierro" (no usa la palabra nuestro, sino mi). De igual forma, los pobladores de la Ciudad del Hierro reconocen la riqueza de esta. Cuando llega a sus puertas un mensajero de Asano pide lo dejen pasar, pero una de las mujeres en la barricada le responde: "Mi señora le quitó esta montaña a los dioses jabalíes y bestias gigantescas, ahora es algo valioso y ustedes quieren robárselo".

Las armas, tipo fusiles que funcionan con pólvora y disparan bolas de hierro, juegan también un papel fundamental y son casi omnipresentes en las escenas de Lady Eboshi. Parte de 
los recursos de la Ciudad del Hierro son destinados al diseño y fabricación de prototipos de fusiles más ligeros, especialmente para las mujeres (tarea que desempeñan de buen agrado los leprosos) para así defenderse de los samuráis de Asano y enfrentarse a los dioses del bosque.

Los diálogos y discursos anteriormente descritos revelan la clara polaridad que existe de parte de la Ciudad del Hierro contra el Shishigami y los demás dioses del bosque. Situación que, como ya se comentaba, recibe la misma respuesta, la polarización de estos contra Lady Eboshi, la ciudad y los humanos en general. Quizás el momento más representativo de esta situación y su afectación para ambos bandos se evidencia cuando San entra a la ciudad e intenta matar a Lady Eboshi, ella sale con dos mujeres armadas con fusiles y le dice: "¿Me oye princesa Mononoke? Estoy aquí. Si desea vengar a su tribu, aquí hay unas mujeres que quieren venganza por sus maridos asesinados por lobos", y una de ellas exclama: "Vamos pequeña bruja, ¡tenemos una cuenta pendiente!".

El tercer sistema de creencias que se presenta es el de los dioses del bosque, encabezado por el Shishigami, pero cuyos representantes en la historia son los dioses menores, Moro, San, Nago, Okkoto y los simios. Quizás no se desarrolla la ideología de estos por completo ya que solo se conoce un aspecto: la misión de proteger el bosque del Shishigami de las acciones de los humanos a quienes han decido eliminar, y el creer también que es imposible lograr una convivencia tranquila entre ambos bandos. Esto se manifiesta, por ejemplo, en las palabras de San cuando Ashitaka huye con ella de la Ciudad del Hierro: "¿Por qué no me dejaste que la matara? [...] ¡Haría cualquier cosa para sacar a los humanos de este bosque!"; también en las palabras de los simios cuando ellos le piden a San y a los cachorros de lobo que le entreguen a Ashitaka para comerlo: "Simios plantan árboles... hombres cortan árboles... el bosque no regresa. Si matamos hombres, salvamos el bosque"; o cuando Moro y Ashitaka hablan en la caverna: "Y sueño con el día en el que destrozaré la cabeza de esa mujer entre mis mandíbulas".

Sin embargo, la misma mirada puesta en el objetivo y la frustración que les produce no poder conseguirlo pese a sus múltiples esfuerzos, los lleva a perder el control sobre sí mismos $\mathrm{y}$, a algunos, a convertirse en tatarigami o a hacer peticiones descabelladas, como cuando los simios le piden a San que les entregue a Ashitaka para así comerlo y adquirir la fuerza de los humanos.

Un aspecto que llama la atención, es que si bien en varios diálogos de los dioses menores le piden ayuda al Shishigami para vencer a los humanos, este explícitamente en ningún momento, toma partido por algún 
bando. De hecho, al final de la película, su acción destructiva sobre el bosque y la muerte entera y su posterior renacimiento, solo se debe a que los humanos le han cortado su cabeza y este desea recuperarla.

Como ya se mencionaba, en la película se manifiesta la confrontación entre el sistema de creencias o ideología de Ashitaka y la de Lady Eboshi, sin llegar a enemistarse. Se refiere por lo tanto a la intención persuasiva, el intento de hacer cambiar al otro de mentalidad. El primero se sucede cuando Ashitaka llega por primera vez a la Ciudad del Hierro y le dice a ella que ha venido con la intención de observar con los ojos despejados, ella ríe y dice que le mostrará su secreto. Lo lleva a una cabaña donde está el taller de los leprosos que fabrican las armas. Ashitaka, indignado, le dice: "Robaste el bosque del jabalí y lo hiciste un monstruo, ¿ahora crearás odios nuevos con esas pistolas?", a lo que ella responde sin desazón que lamenta lo que a él le sucedió debido a la bala que disparó. La maldición se activa y él intenta tomar la espada para matarla, ella lo ve sin inmutarse y le pregunta: "¿Quiere matarme tu mano derecha?", a lo que él responde: "Para levantar la maldición, mi izquierda lo haría también, pero temo que no pararía ahí".

El segundo enfrentamiento ideológico se manifiesta cuando están en la barricada y ella dispara contra los simios que llegan cada noche a reforestar. Allí Lady Eboshi hace explíci- tamente la invitación a Ashitaka para que se una a su causa: "Ashitaka, ¿te quedarías aquí y trabajarías conmigo?" (nótese que ella no dice trabajarías para mí, sino trabajarías conmigo), a lo que Ashitaka le responde desviando la conversación hacia el Shishigami y su muerte. Una vez más intenta seducirlo al decirle: "Las leyendas dicen que la sangre del Gran Espíritu del Bosque puede curar cualquier cosa, quizás pueda curar a mis pobres leprosos, o tal vez incluso podría salvarte de tu maldición Ashitaka".

El tercer enfrentamiento se sucede cuando Ashitaka alcanza a Lady Eboshi, quien marcha junto con Jiko y sus hombres a cortarle la cabeza al Shishigami. Ashitaka le advierte que los samuráis de Asano han aprovechado su ausencia para atacar a la Ciudad del Hierro, ella le responde si le está mintiendo para que abandone: "Para que no matemos al Espíritu del Bosque, prefieres que vayamos a matar a los samuráis", a lo que Ashitaka le responde furibundo: “ $\mathrm{iNo}$ !, lo que quiero es que los humanos y el bosque vivan en paz".

Otro aspecto que surge en la película es la relación ideología-poder que se manifiesta entre Lady Eboshi y los habitantes de la Ciudad del Hierro. Lady Eboshi es un personaje educado (sabe leer y escribir en caligrafía, y sabe contar), está instruida en las artes militares (conoce de estrategias y tácticas de guerra, combate cuerpo a cuerpo, y sabe de armas); asimismo, 
tiene conocimiento en la extracción, forja y negocio del hierro. Su objetivo es generar más riqueza a partir de este mineral, así como de protegerlo de quien se lo quiera arrebatar. Es calmada, no cae en pánico en situaciones de alto estrés, es leal sin dejar de ser precavida (cumple con las alianzas que ha firmado), además de que cuenta con el respeto y apoyo incondicional de los habitantes de la Ciudad del Hierro, en especial de las mujeres y los leprosos. De la misma manera, Lady Eboshi manifiesta en varias ocasiones lamentar los efectos negativos que sus acciones tienen en otros, como el dejar abandonado a Koroku cuando cayó al barranco o disparar la bala que atormentó a Nago, quien posteriormente maldijo a Ashitaka; sin embargo, sus disculpas carecen del sentimiento de remordimiento, aunque reconoce que es ella la que debe cargar con las consecuencias de dichos actos (como haber recibido ella la maldición de Nago, no Ashitaka).

La percepción que se manifiesta sobre Lady Eboshi es dual, mientras quienes afirman ser sus enemigos la ven como la asesina y destructora de la vida en el Bosque del Shishigami, los pobladores de la ciudad la ven como su benefactora, especialmente, las mujeres y los leprosos.

En el caso de las mujeres, su filiación incondicional hacia ella se evidencia en varios momentos durante la película. La razón se conoce cuando Ashitaka se encuentra cenando con los hombres en la Ciudad del Hierro y le ha prometido a las mujeres visitarlas en su lugar de trabajo. Los hombres comentan que Lady Eboshi las mima demasiado y que a ellos no les agrada la idea de que trabajen en los fuelles de la fundición, ya que consideran que su presencia profana el hierro y entonces le dicen: "Mi señora compra los contratos de toda prostituta que halla"; y otro agrega: "Es amable, eso es todo". Esta es una acción que realiza Lady Eboshi cada vez que encuentra a una meretriz, liberándola así de la vida de los burdeles y llevándola a vivir a la Ciudad del Hierro. Los hombres afirman que es una actitud de amabilidad, pero también, dada la ideología de instrumentalización de Lady Eboshi, compra, de manera sutil, un profundo agradecimiento de las favorecidas. Por otro lado, en la película no se hace referencia en ningún momento al pasado de Lady Eboshi que dé más luz sobre las razones de sus comportamientos y, por ende, si su ideología es tan instrumental como se percibe.

El sentimiento de agradecimiento de las mujeres hacia ella se manifiesta en una escena posterior. Ashitaka llega al fuelle donde trabajan arduamente y conversa con ellas: "Es un trabajo difícil"; "Sí, trabajamos cuatro días seguidos”, responde Toki. “¿Es dura la vida aquí?", pregunta Ashitaka; "Supongo que sí, pero es mejor que la vida en un burdel en la ciudad, ¿verdad?", responde Toki, y otra mujer añade: "Comemos bien y los hombres no nos 
molestan". Ashitaka les responde: "Ya veo". Este mismo sentimiento vuelve a manifestarse cuando llega un mensajero de Asano a las puertas de la ciudad y pide que le abran, las mujeres se burlan y este pide respeto; ellas responden: "No hemos sido respetadas desde el día que nacimos", se infiere por lo tanto que fue algo que recuperaron, que Lady Eboshi les devolvió cuando las liberó de sus contratos.

En otra escena, cuando San ataca la ciudad en búsqueda de Lady Eboshi para matarla, las mujeres, alarmadas, se arman; Toki les dice: "No se asusten, sigan trabajando. El fuego no se debe apagar", esto evidencia un sentimiento de protección y de bienestar hacia Lady Eboshi, teniendo en cuenta cuán importante es para ella, y para la ciudad, la fundición del hierro. Nuevamente el sentimiento de protección hacia Lady Eboshi se hace evidente cuando ella les informa que partirá con Jiko a cortarle la cabeza al Shishigami, las mujeres le dicen: "Déjanos ir contigo", "no confíes en esos hombres" (refiriéndose una a los hombres de Jiko), "Si pasa algo no podemos ayudarte desde aquí", "Aprendimos a disparar"; a lo que ella les pide que justo por eso necesita que se queden, para cuidar y defender a la ciudad de los hombres de Jiko (en quienes no confía) o de los hombres del emperador Mikado.
Aprecio y respeto similar muestran hacia ella la comunidad de los leprosos que habitan en la ciudad. Estos se encargan del diseño y fabricación de armas a petición de Lady Eboshi, para quien es otro tema vital, y la satisfacen en lo que ella les pide. Lady Eboshi no muestra repulsión hacia ellos ni tampoco los demás habitantes de la Ciudad del Hierro que comparten al lado de ellos en el momento de defender la ciudad, e incluso, en una escena, se muestra a Toki comiendo una hogaza de pan que un leproso le ha ofrecido, sacándola de sus ropas. Lady Eboshi también les pide disculpas por presionarlos en su trabajo y les promete que pronto mandará a traerles sake. ${ }^{8}$ Esto se evidencia en la escena donde Ashitaka y Lady Eboshi se encuentran en la cabaña de estos; Osa, uno de los leprosos, interrumpe y dice:

[...] joven, yo también estoy maldito; conozco bien su ira y su dolor, lo sé, pero le ruego que no mate a esta dama. Es la única que nos consideró como seres humanos. Somos leprosos, el mundo nos teme y nos odia, pero ella nos acogió, sin temor a nuestra enfermedad, lavó nuestra carne podrida y nos vendó [...].

De igual manera, así como las mujeres, los leprosos participan en la defensa de la ciudad, ya sea disparando las armas o dándoles mantenimiento.

8 Nombre que se le da en Occidente a la bebida alcohólica japonesa hecha a partir de arroz. En Japón se le conoce como Nihonshu. 
Los hombres en ningún momento manifiestan sentirse en desacuerdo o infelices a nivel general con Lady Eboshi y su gobierno sobre la ciudad. El único momento de resistencia se evidencia en la escena cuando Ashitaka está cenando con ellos y le comentan que no les agrada la idea de que las mujeres trabajen en los fuelles de la fundición, ya que consideran que su presencia profana el hierro, pero no manifiestan intención de boicotearlo. De otro lado, Gonza, el principal lugarteniente de Lady Eboshi, esgrime en varias oportunidades que le brindará protección y cumple con su palabra al cargarla en su espalda cuando esta se ha desmayado por el dolor físico que le causó Moro al haberle arrancado un brazo con sus colmillos, salvándola así de una muerte segura.

Es claro el poder que Lady Eboshi tiene sobre la Ciudad del Hierro, sus habitantes y principal actividad (la explotación de hierro), poder que a su vez está plenamente legitimado por las acciones y discursos de los pobladores y donde la resistencia ocupa un papel que pasa desapercibido. Las relaciones de poder se desarrollan en un marco de consentimiento sobre el otro y no se manifiesta abiertamente el uso de la violencia (aunque no indica que no haya maltrato). De igual forma, las acciones que se pueden percibir como negativas, son disculpadas por los mismos habitantes.

Ejemplo de lo anterior se evidencia en la escena cuando Ashitaka llega por primera vez a la Ciudad del Hierro con Koroku y otro herido, Koroku señala hacia la ciudad alegremente y exclama "Volvimos a las fundiciones de hierro... las fundiciones de Lady Eboshi". Al llegar, los recibe Toki, la esposa de Koroku, quien lo recrimina por haberse fracturado un brazo, pues no podrá manejar los bueyes y cuestiona a Gonza su papel de escolta por "haberlo dejado ahí para morir"; sin embargo, cuando aparece Lady Eboshi y le ofrece disculpas a Koroku por haberlo abandonado, la actitud de Toki cambia y le responde que no hay necesidad de disculparse, que si no hubiera sido por ella los lobos habrían acabado con todos (por ende los sacos de arroz no hubieran llegado y hubieran padecido hambruna).

En la Ciudad del Hierro cada género cumple un rol, mientras que los hombres se encargan de la extracción del hierro en la montaña y de guiar a los bueyes que viajan con Lady Eboshi para traer los sacos de arroz, las mujeres se dedican a trabajar en la fundición del hierro y quedan a cargo de la defensa de la ciudad (junto a los leprosos); sin embargo, lo anterior no indica que no haya roces entre hombres y mujeres. Quizás el momento más representativo de la confrontación entre géneros o la reivindicación del rol que cada género tiene en la comunidad se presenta en el diálogo que se ejecuta cuando Ashitaka está con los hombres en un granero cenando. Un grupo de féminas lo llaman y le dicen que vaya 
a cenar a su casa, un hombre molesto les responde: " $\mathrm{i}$ Arriesgamos nuestras vidas para traer el arroz que comen!", a lo que una de ellas responde: “¿Y quién forjó el hierro que trajo ese arroz? ¡Trabajamos toda la noche con esos fuelles!".

Tanto hombres como mujeres demuestran un sentimiento de pertenencia con respecto a la ciudad, que por ende protege los intereses de Lady Eboshi. En el caso de las mujeres se evidencia especialmente cuando Ashitaka llega de nuevo a la Ciudad del Hierro y encuentra que esta es atacada por los samuráis de Asano aprovechando la ausencia de Lady Eboshi. Ellas le dicen a Ashitaka: "Les aventaremos hierro caliente si es necesario", lo que deja en claro que utilizarán hasta su recurso más preciado para evitar que la ciudad caiga.

En el caso de los hombres, cuando Ashitaka llega a donde han combatido junto con los hombres de Jiko contra los jabalíes de Okkoto, y les avisa que la ciudad ha sido atacada por Asano, toman la iniciativa de rebelarse ante los hombres de Jiko cuando Ashitaka les cuestiona: “Quién es más importante, la cabeza del Shishigami o la Ciudad del Hierro?"

Al final de la película, todo el bosque y la Ciudad del Hierro son arrasados por el Gran Espíritu del Bosque o Shishigami, quien va destruyendo todo a su paso mientras persigue a los que se han llevado su cabeza. Mientras San y Ashitaka, después de luchar contra Jiko y sus hombres, deciden devolvérsela, los sobrevivientes han abandonado la ciudad (por consejo de Ashitaka) y se han refugiado en las aguas del lago. Allí Koroku dice que una vez que queme la fragua todo acabará, a lo que Toki le responde: "Mientras estemos vivos nos las arreglaremos, jvamos!". Una vez vuelven a tierra, Lady Eboshi llega adolorida y sin un brazo y les dice: “¿Pueden creerlo? ¡Salvada gracias a un lobo (refiriéndose a los cachorros de Moro). Alguien traiga a Ashitaka, quiero darle las gracias. Empezaremos de nuevo, construiremos un buen pueblo".

En conclusión, si bien La princesa Mononoke es una obra de ficción y fantasía enmarcada en una época antigua del Japón, las situaciones y conflictos que presenta, así como las ideologías y los juegos de poder que se manifiestan, son elementos que han sido inspirados en la realidad circundante (son situaciones humanas independientes del lado del hemisferio en que se viva). Quizás el éxito de esta obra de Miyazaki se halla precisamente en el grado de identificación que encuentran las personas que la ven, dada la representación de las circunstancias a las que diariamente deben enfrentarse, en cualquiera de los tres roles analizados, y por las decisiones que toman, acertadas o no, para lidiar con estas. 


\section{Bibliografía}

Allipso Monografías (17 de noviembre del 2001). Princesa Mononoke. $<$ http://www.alipso.com/monografias/mononoke_hime/>. [Consulta: 10 de mayo del 2011].

Anime News Network. Princess Mononoke. <http://www.animenewsnetwork.com/encyclopedia/ anime.php?id=197>. [Consulta: 7 de mayo del 2011].

Ávila-Fuenmayor, Franciso (2007). "El concepto de poder en Michel Foucault". Revista A Parte Rei 53. Madrid: Sociedad de Estudios Filosóficos.

Foucault, Michel (1984). “Cómo se ejerce el poder", en Dreyfus, Hubert y Paul Rabinow. Un parcours philosophique. París: Editions Gallimard.

Mager, Elisabeth (2010). "Ideología y poder". Revista Multidisciplina 5.
Ciudad de México: Universidad Nacional Autónoma de México.

MiYazAKI, Hayao (1997). La princesa Mononoke. Estudios Ghibli. The Internet Movie Database IMDb. <http://www.imdb.com/title/ tt0119698/>. [Consulta: 29 de abril del 2011].

Nye, Joseph (2004). Soft Power: The means to success in world politics. Nueva York: Public Affairs Books.

VAN DiJK, Teun (2005). "Ideología y análisis del discurso". Revista Utopía y Praxis Latinoamericana 29. Maracaibo: Universidad de Zulia.

-. (2000). Ideología: una aproximación multidisciplinaria. Barcelona: Gedisa. . (1996). "Análisis del discurso ideológico". Revista Comunicación y Política 6. Ciudad de México: Universidad Autónoma Metropolitana. 